\title{
Determinants of health: the role of the general practitioner?
}

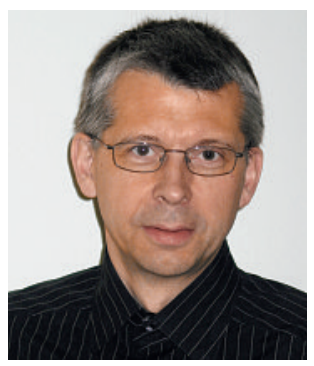

On the $6^{\text {th }}$ of November 2008, the Commission on Social Determinants of Health of the World Health Organisation launched its report: "Closing the gap in a generation: health equity through action on the social determinants of health" [1]. The report observes that there are huge health inequities within countries and between countries, and that these differences are closely linked with the degree of social disadvantage. Social and economic policies have a determining impact on whether a child can grow and develop to its full potential and live a flourishing life, or whether its life will be blighted. The development of a society can be judged by the quality of its population's health, how fairly health care is distributed across the social spectrum, and the degree of protection provided from disadvantage as a result of ill-health. The Commission's overarching recommendations are: improve daily living conditions, tackle the inequitable distribution of power, money and resources and to measure and understand the problem, and to assess the impact of action. The report states that "Health-care systems have better health outcomes when built on Primary Health Care (PHC)" - that is, the PHC model that emphasises both locally appropriate action across the range of social determinants, where prevention and promotion are in balance with investment in curative interventions, and also places an emphasis on the primary level of care with adequate referral to higher levels of care.

As family physicians / general practitioners we see social inequities in health every day in our consultation room: we see the depressed man, unemployed since losing his job at a car-construction plant; we see the child with respiratory infections, due to the fact that it lives in an unhealthy housing condition; we see the young girl with obesity due to inappropriate food consumption and lack of physical activity because there are no green spaces in the neighbourhood. We see it also in statistics: the healthy life expectancy for men in Belgium at the age of 25 is only a further 28.1 years for men with only basic education, and 45.9 years for men with university or higher education [2].

What can we, as family physicians, do to address these social inequities in health? The first thing is that we should not restrict our activity to individual patient care. The World Health Report 2008: "Primary health care, now more than ever" [3], focuses on the central place of health equity in primary health care, and invitesPrimary Care to "put people first". People-centred Primary Care has a focus on health needs, creates an enduring personal relationship, is comprehensive, continuous and person-centred care, takes responsibility for the health of everyone in the community along the life cycle, takes responsibility for tackling determinants of ill-health and sees people as partners in managing their own health and the health of their community. It is here exactly where Family Medicine/General Practice may play an important role as recognised by the resolution "Primary health care, including health systems strengthening" of the 62nd World Health Assembly (WHA62.12) [4].
Nowadays there are new challenges for equity in health: the diseasemanagement approach has led to a focus on vertical disease oriented programs, and less focus on a comprehensive patient approach. This is an important problem in developing countries, where patients have access to certain services only when they have a specific disease (such as HIV/AIDS, malaria and tuberculosis) [5]. We also observe the same developments in European countries. There is disease management for diabetes, COPD and "Cancer plans", which may create a new kind of inequity: the "inequity by disease" where access to care is determined by the diagnosis of the patient. However, as family physicians/general practitioners, we are more frequently faced with multi-morbidity, which means that we have to integrate the different vertical programs at the level of the patient. What we need, in order to address the social determinants of health, is the integration of personal and community health care [6]. We can do this through "Community Oriented Primary Care" (COPC). Starting from our daily encounters in the practice, we can contribute to a systematic assessment of health care needs in the practice population, identification of community health problems, implementation of systematic interventions involving the target population and monitoring effect of changes to ensure that health services are improved and are congruent with community needs. A COPC-team at the local level may design specific interventions to address priority health problems. COPC integrates individual and populationbased care, blending the clinical skills of the practitioner with epidemiology, preventive medicine and health promotion.

The role of the family physician /general practitioner in addressing the social determinants of health is to integrate personal health care and public health, and to organise Primary Care on the principle of care for individuals in the context of an identified population over time. The future of Primary Care, and health care in general, will depend on how effectively Primary Care practices achieve this COPC approach and contribute to equity and social cohesion [7].

\section{References}

1 Commission on Social Determinants of Health. Closing the gap in a generation. Geneva: World Health Organisation (WHO/IER/CSDH/08.1); 2008.

2 Bossuyt N, Gadeyne S, DEboosere P, Van Oyen H. Socio-economic inequalities in health expectancy in Belgium. Public Health. 2004;118(1):3-10.

3 World Health Organization. Primary Health Care: now, more than ever. Geneva: World Health.

4 Anonymous. The historic WHA Resolution on Primary Health Care. Wonca News. 2009;35(3):20-21.

5 De Maeseneer J, van Weel C, Egilman D et al. Funding for primary health care in developing countries: money for disease specific projects could be used to strengthen Primary Care. BMJ. 2008;336:518-9.

6 Van Weel C, De Maeseneer J, Roberts R. Integration of personal and community health care. The Lancet. 2008;372:871-72.

7 Art B, Deroo L, De Maeseneer J. Towards unity for health utilising community oriented Primary Care in education and practice. Educ health. 2007;20:1-10.

\section{Correspondence:}

Prof. Jan De Maeseneer

Department of Family Medicine and Primary Health Care

Gent University, Chairman European Forum for Primary Care

B-9000 Gent

www.euprimarycare.org 